\title{
Fish biology and biotechnology is the source for sustainable aquaculture
}

\author{
GUI Jian-Fang \\ State Key Laboratory of Freshwater Ecology and Biotechnology, Institute of Hydrobiology, Chinese Academy of Sciences, University of \\ Chinese Academy of Sciences, Wuhan 430072, China
}

Received December 9, 2014

Citation: Gui JF. Fish biology and biotechnology is the source for sustainable aquaculture. Sci China Life Sci, 2015, 58: 121-123, doi: $10.1007 / \mathrm{s} 11427-015-4812-9$

The contribution of aquaculture to global food production and security has been widely acknowledged since the start of the 21 st century [1-4]. Global aquaculture production has increased continuously over the last five decades, and particularly in China, aquaculture has become the fastest growing and most efficient agri-sector, with production accounting for more than $70 \%$ of the world's aquaculture output [5,6]. José Graziano da Silva, director-general of the United Nations Food and Agriculture Organization (FAO), stated in The State of World Fisheries and Aquaculture (2014), published by FAO, "Global fish production continues to outpace world population growth, and aquaculture remains one of the fastest-growing food producing sectors. If responsibly developed and practiced, aquaculture can generate lasting benefits for global food security and economic growth" [6]. The future of fish and aquaculture potentials have been the subject of extensive discussion [1-4].

Reviewing the process over the past 50 years, the rapid growth in aquaculture is clearly a result of developments in fish biology and biotechnology. As a multidisciplinary subject for studying the roles and mechanisms of fish phylogenesis, development, growth, reproduction and behavior, and thereby exploiting the biotechnology applicable to genetic breeding and disease prevention, fish biology and biotechnology has provided the innovation and technology for rapid development of the aquaculture industry. For example, the breakthrough in artificial propagation techniques for the

email: jfgui@ihb.ac.cn "four important domestic fish"-silver, bighead, grass and black carp - in the early 1960s [7] established the scientific and technological basis for fry and fingerling production of other fish and aquatic species. Since the 1980s, biotechnological innovations and developments have provided sustained motivation for the establishment of genetic breeding, disease control and aquaculture seed programs [8]. Many novel aquatic varieties that have played a major role in aquaculture are the results of comprehensive and systematic studies on the biological characteristics of these species. For instance, most farmed varieties of the common and gibel carp were selected and developed on the basis of a thorough understanding of their genetic background $[9,10]$.

Over the last 20 years, significant progress has been made in fish biology and biotechnology, especially in the field of fish genetic breeding. To introduce these advances, the editorial committee has invited several scientists from the Institute of Hydrobiology of the Chinese Academy of Sciences, the College of Fisheries of Huazhong Agricultural University, Heilongjiang Fishery Institute of the Chinese Academy of Fishery Sciences, and the College of Life Sciences of Hunan Normal University to jointly contribute seven review articles to highlight a number of hot topics in this field.

Mei Jie and Gui Jian-Fang [11] provide a commentary review on the genetic basis and biotechnological manipulation of sexual dimorphism and sex determination in fish. They summarize recent breakthroughs and advances in this 
field, including several successful cases of biotechnological manipulation for sex control breeding, and consider some promising prospects for future research.

Yin Zhan and his colleagues [12] collate recent work on the somatotropic endocrine axis of fish, and review some recent advances in the endocrine regulation of pituitary growth hormone $(\mathrm{GH})$ and extrapituitary aspects of the $\mathrm{GH} /$ insulin-like growth factor (IGF) system.

Xiao WuHan [13] summarizes novel progress in research of the hypoxia signaling pathway and its regulation, as well as the mechanism of hypoxia adaptation in fish.

Based on their research experience of more than 20 years, Zhang QiYa and Gui Jian-Fang [14] review and compare the genomic data of diverse aquatic viruses, such as irido-, herpes-, reo- and rhabdoviruses, and outline some major advances on virus-host interactions in the infected aquaculture species.

Sun YongHua and Zhu ZuoYan, as well as their colleagues [15], review the history of fish-breeding methods based on classical genome manipulation, including polyploidy breeding and nuclear transfer, and emphasize the development and application of fish directional breeding based on transgenic technology and recently developed genome editing technologies.

Tong JinGou and Sun XiaoWen [16] concisely summarize current genetic and genomic analyses for economically important traits, and discuss future directions and prospects of genomics and next-generation sequencing technology for fish molecular breeding.

Liu ShaoJun and Liu Yun and their colleagues [17] appraise the biological foundations and applications of selective breeding technologies, including traditional selective, molecular marker-assisted, genome-wide selective and sex control breeding, and review and discuss the research status of and known problems in fish genetic breeding.

Finally, I would like to cordially thank all the authors for contributing review articles on this topic, and wish that the advances in fish biology and biotechnology will become an inexhaustible source for the development of sustainable aquaculture and fisheries.

1 Naylor RL, Goldburg RJ, Primavera JH, Kautsky N, Beveridge MC, Clay J, Folke C, Lubchenco J, Mooney H, Troell M. Effect of aquaculture on world fish supplies. Nature, 2000, 405: 1017-1024

2 Pauly D, Christensen V, Guénette S, Pitcher TJ, Sumaila UR, Walters CJ, Watson R, Zeller D. Towards sustainability in world fisheries. Nature, 2002, 418: 689-695

3 James HT, Geoff LA. Fishes as food: aquaculture's contribution. EMBO Rep, 2001, 21: 958-963

4 Worm B, Branch TA. The future of fish. Trends Ecol Evol, 2012, 27: 594-599

5 Gui JF, Zhu ZY. Molecular basis and genetic improvement of economically important traits in aquaculture animals. Chin Sci Bull, 2012, 57: 1751-1760

6 Food and Agriculture Organization of the United Nations. The State of World Fisheries and Aquaculture 2014. Rome, 2014

7 Wu HW, Zhong L. Progress and achievement on artificial proliferation of grass carp, black carp, silver carp and big head carp in China. Chin Sci Bull, 1964, 9: 900-907

8 Wu CJ, Gui JF. Fish Genetics and Breeding Engineering (in Chinese). Shanghai: Shanghai Scientific and Technical Publishers, 1999

9 Gui JF, Zhou L. Genetic basis and breeding application of clonal diversity and dual reproduction modes in polyploid Carassius auratus gibelio. Sci China Life Sci, 2010, 53: 409-415

10 Liu SJ. Distant hybridization leads to different ploidy fishes. Sci China Life Sci, 2010, 53: 416-425

11 Mei J, Gui JF. Genetic basis and biotechnological manipulation of sexual dimorphism and sex determination in fish. Sci China Life Sci, 2015, 58: 124-136

12 Dai XY, Zhang W, Zhuo ZJ, He JY, Yin Z. Neuroendocrine regulation of somatic growth in fishes. Sci China Life Sci, 2015, 58: $137-147$

13 Xiao WH. The hypoxia signaling pathway and hypoxic adaptation in fishes. Sci China Life Sci, 2015, 58: 148-155

14 Zhang QY, Gui JF. Virus genomes and virus-host interactions in aquaculture animals. Sci China Life Sci, 2015, 58: 156-169

15 Ye D, Zhu ZY, Sun YH. Fish genome manipulation and directional breeding. Sci China Life Sci, 2015, 58: 170-177

16 Tong JG, Sun XW. Genetic and genomic analyses for economically important traits and their applications in molecular breeding of cultured fish. Sci China Life Sci, 2015, 58: 178-186

17 Xu K, Duan W, Xiao J, Tao M, Zhang C, Liu Y, Liu SJ. Development and application of biological technologies in fish genetic breeding. Sci China Life Sci, 2015, 58: 187-201

Open Access This article is distributed under the terms of the Creative Commons Attribution License which permits any use, distribution, and reproduction in any medium, provided the original author(s) and source are credited. 


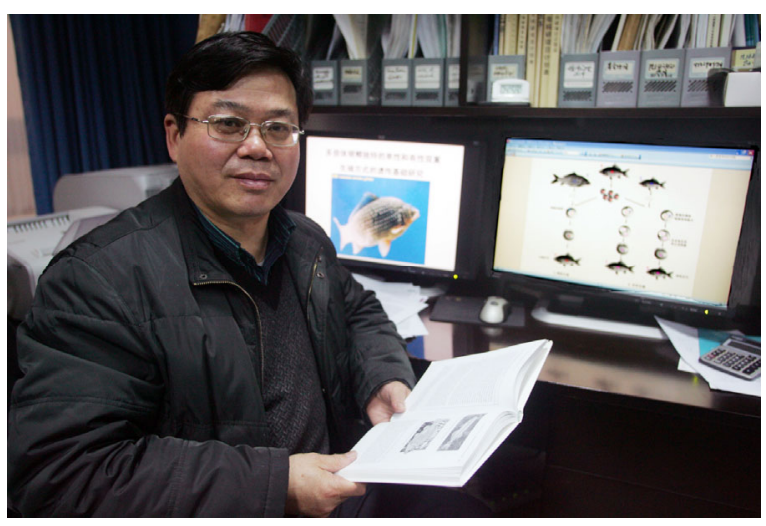

\section{Biographical Sketch}

Dr. Gui Jian-Fang is a professor at the Institute of Hydrobiology, Chinese Academy of Sciences. He obtained his Ph.D. from the Institute of Hydrobiology, Chinese Academy of Sciences, and completed a two-year postdoctoral fellowship at the University of California, San Diego, USA. He is a former director of the Institute of Hydrobiology, Chinese Academy of Sciences (1999-2007) and a former director of the State Key Laboratory of Freshwater Ecology and Biotechnology (2001-2011). Dr. Gui is currently vice president of the China Zoological Society, vice president of the Chinese Society for Oceanology and Limnology, and president of the Chinese Ichthyological Society. He serves as chief editor of Acta Hydrobiologica Sinica and an editorial board member of several journals, including Gene, Science China Life Sciences and Chinese Science Bulletin. He is vice chairman of the National Certification Committee for Aquatic Varieties. His research has focused on fish biology and biotechnology with particular emphasis on fish genetic breeding. Dr. Gui has published more than 350 peer-reviewed research papers, including more than 190 SCI-indexed papers. He has won numerous awards and honors including the second award of National Natural Sciences in China (2011), China Youth Science and Technology Award (1988), the National Science Foundation for Distinguished Young Scholars (1994), the First Young Scientist Award of Chinese Academy of Sciences (1995), the Distinguished Young Scholar Award of Qiu-Shi Science and Technology Foundation (1996), the National Labor Day Working Medal (2009), and the Distinguished Scientist with Outstanding Contribution for "11th Five-year" National Science and Technology Programs (2011). He was elected an Academician of the Chinese Academy of Sciences in 2013. 